\title{
The impact of operative time on the outcomes of necrotizing soft tissue infections: a multicenter cohort study
}

\author{
Femke Nawijn ${ }^{1 *} \mathbb{D}$, Mark van Heijl ${ }^{1,2}$, Jort Keizer ${ }^{3}$, Paul J. van Koperen ${ }^{4}$ and Falco Hietbrink ${ }^{1}$
}

\begin{abstract}
Background: The primary aim of this study was to identify if there is an association between the operative time of the initial debridement for necrotizing soft tissue infections (NSTIS) and the mortality corrected for disease severity.

Methods: A retrospective multicenter study was conducted of all patients with NSTIs undergoing surgical debridement. The primary outcome was the 30-day mortality. The secondary outcomes were days until death, length of intensive care unit (ICU) stay, length of hospital stay, number of surgeries within first 30 days, amputations and days until definitive wound closure.

Results: A total of 160 patients underwent surgery for NSTIs and were eligible for inclusion. Twenty-two patients (14\%) died within 30 days and 21 patients (13\%) underwent an amputation. The median operative time of the initial debridement was 59 min (IQR 35-90). In a multivariable analyses, corrected for sepsis just prior to the initial surgery, estimated total body surface (TBSA) area affected and the American Society for Anesthesiologists (ASA) classification, a prolonged operative time (per $20 \mathrm{~min}$ ) was associated with a prolonged ICU ( $\beta 1.43,95 \% \mathrm{Cl} 0.46-2.40 ; p=0.004)$ and hospital stay $(\beta 3.25,95 \% \mathrm{Cl} 0.23-6.27 ; p=0.035)$, but not with 30 -day mortality. Operative times were significantly prolonged in case of NSTIs of the trunk ( $p=0.044)$, in case of greater estimated TBSA affected $(p=0.006)$ or if frozen sections and/or Gram stains were assessed intra-operatively $(p<0.001)$.
\end{abstract}

Conclusions: Prolonged initial surgery did not result in a higher mortality rate, possible because of a short duration of surgery in most studied patients. However, a prolonged operative time was associated with a prolonged ICU and hospital stay, regardless of the estimated TBSA affected, presence of sepsis prior to surgery and the ASA classification. As such, keeping operative times as limited as possible might be beneficial for NSTI patients.

Keywords: Necrotizing soft tissue infections, Necrotizing fasciitis, Severe necrotizing soft tissue infection, Mortality, Operative time, Damage control

\section{Background}

Necrotizing soft tissue infections (NSTIs) are potentially lethal infections that cause necrosis of the subcutaneous fat, fascia and/or muscles. NSTIs are notorious for their acute onset and progressive nature, requiring prompt

\footnotetext{
*Correspondence: f.nawijn-3@umcutrecht.nl

${ }^{1}$ Department of Surgery, University Medical Center Utrecht, Utrecht, The Netherlands

Full list of author information is available at the end of the article
}

treatment [1]. Bacteria involved in NSTIs can spread rapidly along the fascial planes causing rapid progression and systemic complications [2]. A recent meta-analyses showed that early surgical debridement is vital for lowering mortality rates, since surgery within six hours after presentation lowered the mortality rate for NSTIs with almost $50 \%$ [3]. In this review, it was also attempted to identify a relationship between the operative time of the initial surgery for the NSTI and the mortality, the 
results for this analysis were too scarce. Even though only three studies reported on operative times, these results revealed a possible association between the duration of the initial surgery and the outcome of the NSTI [3-6]. It is well established in trauma and emergency surgery that prolonged operating times potentially lead to higher complication rates [7-9]. Therefore, in critical ill patients with physiological derangement, the damage control surgery principles are more widely applied, specifically in trauma. Damage control procedures are in their initial stage not aimed at definitive repair, but rather aimed to perform limited interventions to control the situation and to recover the patient's physiology preferable within an operating time of $90-120 \mathrm{~min}[10,11]$. In trauma patients, this commonly refers to hemorrhage control and prevention of contamination. In NSTI patients this would refer to adequate and rapid source control with temporary closure [10]. After initial surgical control and resuscitation, secondary surgical procedures are required to perform reconstructions and definitive wound closure. However, since information on the association between operative time of the initial debridement for NSTIs and its outcomes is scarce, the aim of this study was to identify if such an association exists and to determine if the principles of damage control surgery are beneficial to NSTI patients.

\section{Methods}

The institutional review board of the initiating hospital provided a waiver (WAG/mb/20/012110) for consent for retrospective data collection. The board of all participating studies approved data collection. A protocol was a priori written, however, not published.

\section{Study design}

A retrospective cohort study of all patients with confirmed NSTIs who underwent their initial surgical debridement at one of the four participating study hospitals (an academic medical center and three large peripheral hospitals) between January $1^{\text {st }}, 2010$ and December $31^{\text {st }}, 2019$ was performed. NSTI refers to the necrotizing forms of fasciitis, myositis and cellulitis. The NSTI had to be confirmed by either operative findings and/or histopathologic tissue findings and/or microbiology results $[12,13]$. Patients younger than 18 years at time of onset of the NSTI were excluded, as well were patients who were lost to follow-up after their initial debridement (e.g. due to transfer of patient to another hospital) or if operative times were missing. Eligible patients were identified using different methods per hospital which are outlined in Additional File 1. The study size was based on the number of eligible patients presenting to the study hospitals in the aforementioned study period.

\section{Data collection}

The patient demographics extracted from the medical charts included age, sex, the American Society of Anesthesiologist (ASA) classification. The extracted diseaserelated characteristics were location of the infection, estimated total body surface area (TBSA) affected, cultured micro-organisms, and laboratory results and hemodynamic parameters just prior to the initial surgery. The TBSA affected was estimated using the rule of nines for burn injuries [14]. Operative times of the initial surgery (incision to end surgery and time in het operating room), (primary or secondary) amputation, if a skin sparing operating technique was used (as reported in the operative note), complications, days until wound closure and mortality (including cause of death and time from initial surgery to death) were among the treatment related variables extracted. If possible, based on the available hemodynamic parameter and laboratory results, the Laboratory Risk Indicator for Necrotizing fasciitis (LRINEC), the sequential organ failure assessment (SOFA) score, the quick sequential organ failure assessment (qSOFA) score and Acute Physiologic Assessment and Chronic Health Evaluation (APACHE) II score were calculated prior to the initial surgery. For the laboratory results and hemodynamic parameters prior to surgery, only values reported within twelve hours prior to the start of the surgery were analyzed. Patients were determined to be septic prior to surgery if either the qSOFA or the SOFA was scored two or higher [15]. The primary outcome of this study was the 30-day mortality. The secondary outcomes were days until death, length of ICU stay, length of hospital stay, number of surgeries within first 30 days, the need for an amputation during re-exploration and days until definitive wound closure.

\section{Statistical analysis}

Normally distributed continuous variables are presented with means and standard deviations (SD), and, if more appropriate based on normality, presented with medians and interquartile ranges (IQR). Categorical variables are presented with frequencies and percentages. Missing data were handled using pairwise deletion. Multivariable analyses (either logistic or linear) were used to determine the association between the operative time per $20 \mathrm{~min}$ and the primary and secondary outcomes. For the multivariable analysis, the analysis were corrected for sepsis prior to surgery (imputed as dichotomous variable), ASA classification (imputed as categorical variable) and the TBSA (imputed as continuous variable). These variables were a-priori chosen since the presence of sepsis and the amount and severity of comorbidities influence outcomes are well-known factors associated with outcome such as 
mortality and length of intensive care and hospital stay [16-19]. The TBSA was chosen since it is very plausible that the area that has to be resected will influence the operative time. The number of covariates chosen to be included in the multivariate analysis was depended on the primary outcome. For the assessment of factors influencing the operative time and mortality, the Mann-Whitney $\mathrm{U}$ test was used for dichotomous independent variables, the Kruskal Wallis test for nominal independent variables and the Chi-squared test for trend for ordinal independent variables. For all analyses, a two-sided $p$-value $<0.05$ was considered statistically significant. Data will be analyzed using STATA (StataCorp. 2013. Stata Statistical Software: Release 13. College Station, TX: StataCorp LP).

\section{Results}

A total of 187 patients with NSTIs were identified, of which 160 were eligible for this study (Fig. 1). The mean age of the included patients was $56 \pm 16$ years. Most patients had no or minor comorbidities (ASA I or II: $\mathrm{n}=98,62 \%)$. The lower extremity was most commonly affected by the NSTI $(n=75,45 \%)$. The estimated TBSA affected ranged between 1 and $30 \%$ with a median of $3 \%$ (IQR 2-6\%). Most NSTIs were monomicrobial infection, with group A streptococcus being identified as causative pathogen in almost half of all NSTIs $(n=74$, 46\%) (Table 1).

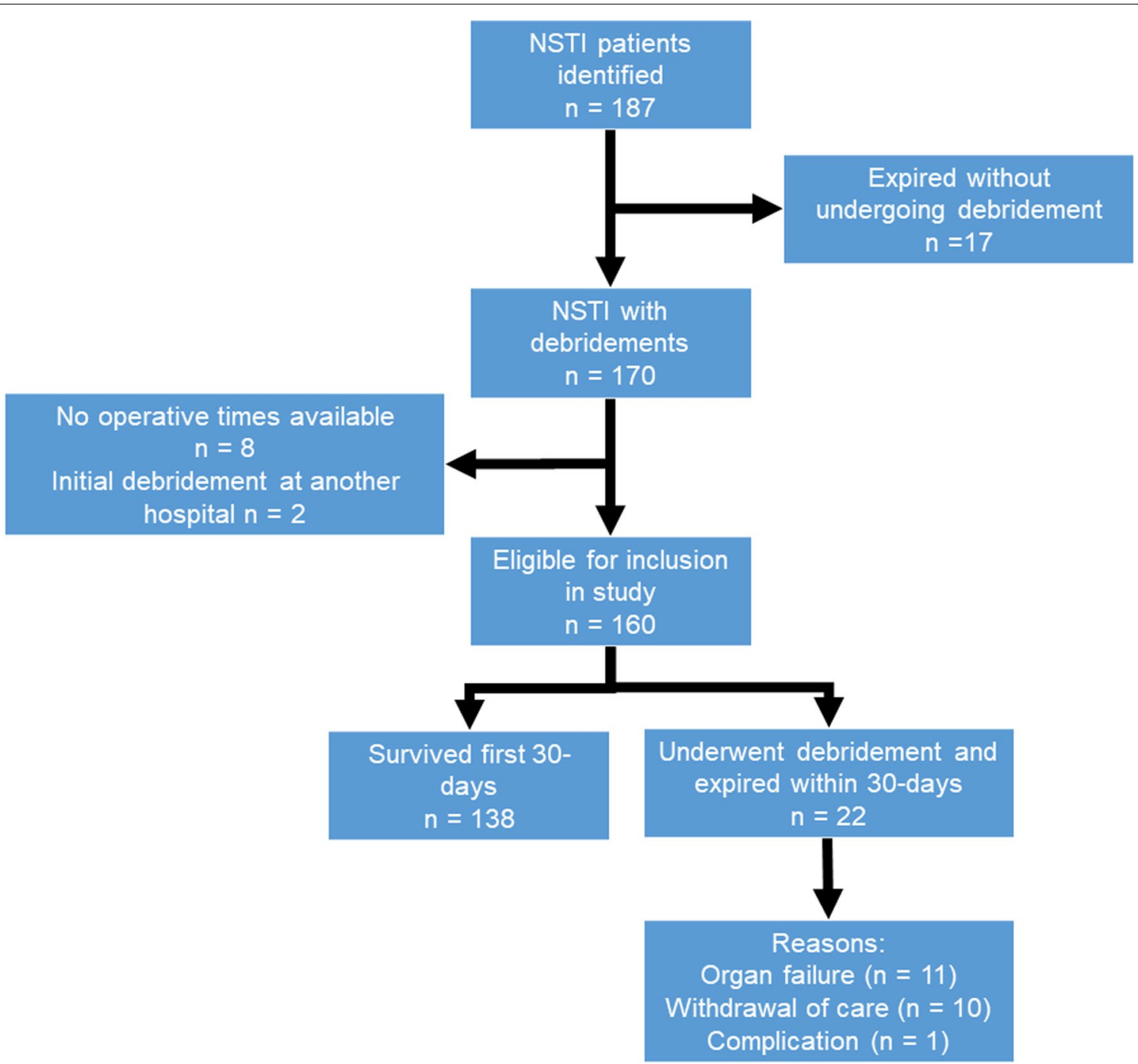

Fig. 1 Inclusion flowchart of necrotizing soft tissue infections patients undergoing surgery 
Table 1 Patient characteristics of necrotizing soft tissue infection patients undergoing surgery

\begin{tabular}{|c|c|}
\hline & $\begin{array}{l}n=160 \\
(100 \%)\end{array}$ \\
\hline Age in years, mean $\pm S D$ & $56 \pm 16$ \\
\hline Male sex, n (\%) & $108(68)$ \\
\hline \multicolumn{2}{|l|}{ ASA classification } \\
\hline । & $33(21)$ \\
\hline$\|$ & $65(41)$ \\
\hline III & $52(32)$ \\
\hline IV & $10(6)$ \\
\hline \multicolumn{2}{|l|}{ Location of NSTI, n (\%) } \\
\hline Head/neck & $8(5)$ \\
\hline Trunk & $16(10)$ \\
\hline Perineum & $44(27)$ \\
\hline Upper extremity & $19(12)$ \\
\hline Lower extremity & $72(45)$ \\
\hline Multiple body areas involved & $1(1)$ \\
\hline Estimated TBSA affected in $\%^{\mathrm{a}}$, median (IQR) & $3(2-6)$ \\
\hline $0-5 \%$ & $111(70)$ \\
\hline $6-10 \%$ & $36(23)$ \\
\hline $11-15 \%$ & $7(4)$ \\
\hline$>15 \%$ & $4(3)$ \\
\hline \multicolumn{2}{|c|}{ Cultured micro-organism from incisional biopsy, n (\%) } \\
\hline Monomicrobial & $102(64)$ \\
\hline Group A Streptococcus & $74(72)$ \\
\hline Other Streptococcus spp. & $10(10)$ \\
\hline Staphylococcus aureus & $7(7)$ \\
\hline $\begin{array}{l}\text { Escherichia coli } \\
\text { Pseudomonas spp. } \\
\text { Clostridium spp. } \\
\text { Other }\end{array}$ & $\begin{array}{l}3(3) \\
2(2) \\
1(1) \\
5(5)\end{array}$ \\
\hline Polymicrobial & $55(34)$ \\
\hline $\begin{array}{l}\text { Escherichia coli involved } \\
\text { Pseudomonas spp. involved } \\
\text { Clostridium spp. involved }\end{array}$ & $\begin{array}{l}18(32) \\
3(5) \\
7(12)\end{array}$ \\
\hline Negative cultures & $3(19)$ \\
\hline
\end{tabular}

ASA American Society of Anesthesiologists; IQR Interquartile Range; NSTI Necrotizing Soft Tissue Infection; SD Standard Deviation; TBSA Total Body Surface Area

a 2 cases missing. ${ }^{b}$ Acinetobacter baumanii, Enterobacter cloacae, Neisseria meningitidis, Proteus vulgaris and Vibrio parahaemolyticus

\section{Hemodynamic parameters and clinical chemistry prior to surgery}

Just prior to the initial surgery, 52 patients (34\%) had a systolic blood pressure lower than $100 \mathrm{mmHg}, 81$ patients $(52 \%)$ were tachycardic and 40 patients (40\%) were tachypnoeic. The mean base excess for all patients was $-6.1 \pm-5.8$. See Table 2 for the mean values of the hemodynamic and laboratory parameters. The median LRINEC score was 7 (IQR 6-9, 22 patients (20\%) had a score $<6)$. Fifty patients $(33 \%)$ were determined to be septic just prior to their initial surgery for the NSTI, of which 21 (42\%) received continuous vasopressors to maintain an adequate mean arterial pressure (Table 2).In Table 3, the factors associated with mortality in patients who were able to undergo surgery for NSTIs are reported. Which shows that within this group of patients mortality is mainly associated with a greater TBSA $(p=0.002)$, higher APACHE II scores $(p=0.018)$ and sepsis prior to surgery $(n=0.047)$.

\section{Impact of operative times on outcomes}

The median operative time of the initial debridement for NSTIs was $59 \mathrm{~min}$ (IQR 35-90, range 10-400 min), while 35 initial surgeries (22\%) took longer than $90 \mathrm{~min}$ (Fig. 2). A total of 22 patients (14\%) died within 30 days after presentation. The median duration of the initial surgery for deceased patients was $62 \mathrm{~min}$ (IQR 45-90) and $57 \mathrm{~min}$ for survivors (IQR 31-89, $p=0.335$ ). Post-hoc power analysis of our primary objective, the association between the operative time and 30-day mortality, showed a medium effect size $(\mathrm{d}=0.30)$ and a power of 0.28 $(\alpha=0.05, \beta 0.72)$. Surgeries that took longer than $140 \mathrm{~min}$ had a two-fold higher mortality rate $(4 / 15,27 \%)$ compared to surgeries shorter than $140 \mathrm{~min}(18 / 126,13 \%)$, however this differences was not significant with the current sample size $(p=0.133)$.

During 36 surgeries (23\%), frozen sections and/or Gram stains were intra-operatively assessed for diagnostic purposes. The use of frozen section and/or gram stain resulted in a shorter time from presentation to diagnosis (4 h (IQR 3-15) vs. 7 h (IQR $4-26), p=0.035)$, but resulted in significantly longer operative times $(p<0.001)$. In 36 cases $(23 \%)$ skin sparing operative techniques were utilized, those surgeries had a median operative time of 46 min (IQR 30-90, range 15-400, $p=0.715$ ), but was mostly used in cases with relatively low estimated TBSA affected (median 4\%, IQR 2-6\%). In case of a NSTI affecting the trunk, the initial surgery was significantly prolonged compared to other body locations $(p=0.044)$, this also applied to cases in which a greater estimated TBSA was affected $(p=0.006)$ (Table 4 and 5).

A multivariable logistic regression, which was corrected for the presence of sepsis just prior to the initial surgery, estimated TBSA and the ASA classification, found no significant association between the operative time and 30-day mortality $(\beta 0.14,95 \% \mathrm{CI}$ $-0.06-0.33 ; p=0.170)$. There were also no significant associations between the operative time and the need for an amputation during re-exploration ( $\beta$ 0.11, 95\% CI $-0.12-0.35 ; p=0.356)$, number of surgeries within first 30 days $(\beta 0.01,95 \% \mathrm{CI}-0.14-0.16 ; p=0.873)$ or days until definitive wound closure $(\beta-2.77,95 \%$ CI $-7.64-2.09 ; p=0.262)$. However, within the linear 
Table 2 Hemodynamic parameters and laboratory results prior to surgery in necrotizing soft tissue infection patients

\begin{tabular}{|c|c|c|c|}
\hline & $\mathbf{n}$ & Mean \pm SD or Median (IQR) & Reference values \\
\hline \multicolumn{4}{|l|}{ Hemodynamic parameters } \\
\hline Systolic blood pressure & 155 & $114 \pm 24$ & $90-120 \mathrm{mmHg}$ \\
\hline Diastolic blood pressure & 155 & $65 \pm 17$ & $60-80 \mathrm{mmHg}$ \\
\hline Mean arterial pressure & 155 & $81 \pm 18$ & $70-100 \mathrm{mmHg}$ \\
\hline Heart rate & 155 & $104(88-120)$ & $60-100$ beats/minute \\
\hline Respiratory rate & 100 & $20(15-25)$ & 12-20 breaths/minute \\
\hline Temperature & 156 & $37.4 \pm 1.1$ & $36-38^{\circ} \mathrm{C}$ \\
\hline \multicolumn{4}{|l|}{ Blood test results } \\
\hline Hemoglobin & $\begin{array}{l}94 \\
46\end{array}$ & $\begin{array}{l}\text { of } 8.0 \pm 1.5 \\
\text { o } 7.2 \pm 1.2\end{array}$ & $\begin{array}{l}\text { o } 8.6-10.7 \mathrm{mmol} / \mathrm{L} \\
\text { o7.4-9.6 mmol/L }\end{array}$ \\
\hline Hematocrit & 134 & $37 \pm 7$ & $41-50 \%$ \\
\hline Platelet count & 118 & $183(137-264)$ & $150-450 \times 10^{9} / \mathrm{L}$ \\
\hline White blood cell count & 146 & $15.4(10.2-20.5)$ & $0.8-4.0 \times 10^{9} / \mathrm{L}$ \\
\hline Sodium & 130 & $135 \pm 6$ & $136-146 \mathrm{mmol} / \mathrm{L}$ \\
\hline Potassium & 130 & $4.0 \pm 0.6$ & $3.8-5.0 \mathrm{mmol} / \mathrm{L}$ \\
\hline Creatinine & 136 & $125(78-184)$ & 64-104 $\mu \mathrm{mol} / \mathrm{L}$ \\
\hline Total bilirubin & 82 & $16(9-28)$ & $3-21 \mathrm{mmol} / \mathrm{L}$ \\
\hline Lactate & 65 & $3.5(2.2-5.4)$ & $0.0-2.2 \mathrm{mmol} / \mathrm{L}$ \\
\hline Lactate dehydrogenase & 85 & $235(194-329)$ & $0-250 \mathrm{U} / \mathrm{L}$ \\
\hline Creatine kinase & 61 & $389(75-1333)$ & $0-170 \mathrm{U} / \mathrm{L}$ \\
\hline C-reactive protein & 146 & $296 \pm 142$ & $0-10 \mathrm{mg} / \mathrm{L}$ \\
\hline Glucose & 114 & $7.0(5.9-8.4)$ & $3.6-5.6 \mathrm{mmol} / \mathrm{L}$ \\
\hline \multicolumn{4}{|l|}{ Arterial blood gas results ${ }^{\mathrm{a}}$} \\
\hline $\mathrm{pH}$ & 91 & $7.36(7.28-7.44)$ & $7.37-7.45$ \\
\hline $\mathrm{PaO}_{2}$ & 81 & $89(80-132)$ & $70-100 \mathrm{mmHg}$ \\
\hline $\mathrm{PaCO}_{2}$ & 81 & $33(27-40)$ & $35-45 \mathrm{mmHg}$ \\
\hline Bicarbonate & 91 & $19 \pm 5$ & $22.0-28.0 \mathrm{mmol} / \mathrm{L}$ \\
\hline Base excess & 91 & $-6.1 \pm 5.8$ & $-3.0-3.0 \mathrm{mmol} / \mathrm{L}$ \\
\hline \multicolumn{4}{|l|}{ Risk scores } \\
\hline LRINEC score & 108 & $7(6-9)$ & Range 0-13 \\
\hline SOFA score & 54 & $5 \pm 3$ & Range 0-24 \\
\hline $\begin{array}{l}\text { APACHE II score } \\
\text { Septic upon admission, n (\%) } \\
\text { Septic prior to surgery, n (\%) }\end{array}$ & $\begin{array}{l}55 \\
152 \\
153\end{array}$ & $\begin{array}{l}13 \pm 6 \\
47(31) \\
50(33)\end{array}$ & $\begin{array}{l}\text { Range } 0-67 \\
\text { qSOFA }<2 \text { and/or SOFA score }<2 \\
\text { qSOFA }<2 \text { and/or SOFA score }<2\end{array}$ \\
\hline
\end{tabular}

APACHE Acute Physiologic Assessment and Chronic Health Evaluation, IQR Interquartile Range, LRINEC Laboratory Risk Indicator for Necrotizing fasciitis, qSOFA Quick Sequential Organ Failure Assessment, SDStandard Deviation, SOFA Sequential Organ Failure Assessment

${ }^{a}$ If only a venous blood gas was available, only $\mathrm{pH}$, bicarbonate and base deficit were extracted

multivariable analysis, each 20 min increase in operative time resulted in an increase of the ICU stay with 1.4 days ( $\beta$ 1.43, 95\% CI 0.46-2.40; $p=0.004$ ) and an increase of the hospital stay with 3.3 days $(\beta 3.25,95 \%$ CI $0.23-6.27 ; p=0.035$ ) (Table 6). The same multivariate analyses, corrected for operative time of the initial surgery, sepsis prior to surgery and ASA classification, showed that an increased estimated TBSA resulted in higher mortality rates $(\beta \quad 0.16,95 \%$ CI $0.04-0.27$; $p=0.007$ ), longer hospital length of stay ( $\beta 6.37,95 \%$ CI $4.19-8.55 ; p<0.001)$ and more surgeries within the first 30 days $(\beta 0.25,95 \%$ CI $0.13-0.37 ; p<0.001)$. Also sepsis prior to surgery was independently associated with adverse outcomes (corrected for operative time of the initial surgery, estimated TBSA and ASA classification), being an increase in ICU stay with 9 days ( $\beta$ 9.19, 95\% CI 4.91-13.47; $p<0.001)$ and the hospital stay with 17 days ( $\beta 17.17,95 \%$ CI 3.41-30.94; $p=0.015$ ). Septic patients who died $(\mathrm{n}=11)$ did not have a significantly lower operative time compared to septic patients who survived $(\mathrm{n}=39)$ (median of $60 \mathrm{~min}(\mathrm{IQR} 45-76)$ vs. median $68 \min (42-100), p=0.504)$. 
Table 3 Factors associated with mortality in necrotizing soft tissue infection patients who are able to undergo surgery

\begin{tabular}{|c|c|c|c|}
\hline & $\begin{array}{l}\text { Survived } \\
(n=138,86 \%)\end{array}$ & $\begin{array}{l}\text { Deceased } \\
(n=22,14 \%)\end{array}$ & $p$ value \\
\hline ASA classification, n (\%) & & & 0.057 \\
\hline |-I| & $89(91)$ & $9(9)$ & \\
\hline III-IV & $49(79)$ & $13(21)$ & \\
\hline \multicolumn{4}{|l|}{ Location of the NSTI, n (\%) } \\
\hline Extremities & $78(86)$ & $13(14)$ & 0.464 \\
\hline Trunk & $13(81)$ & $3(19)$ & 1.000 \\
\hline Perineum & $39(89)$ & $5(11)$ & 0.798 \\
\hline Total body area affected ${ }^{\mathrm{a}}$, median (IQR) & $3(2-5)$ & $7(3-10)$ & 0.002 \\
\hline Monomicrobial NSTI ${ }^{\mathrm{b}}, \mathrm{n}(\%)$ & $86(84)$ & $16(16)$ & 0.478 \\
\hline Polymicrobial NSTI', n (\%) & $49(89)$ & $6(11)$ & 0.478 \\
\hline SOFA score prior to surgery ${ }^{c}$, median (IQR) & $5(2-7)$ & $6(6-9)$ & 0.146 \\
\hline APACHE II score prior to surgery ${ }^{d}$, median (IQR) & $11(9-15)$ & $13(13-17)$ & 0.018 \\
\hline Time from presentation to surgery, median (IQR) & $2(0-3)$ & $1(0-3)$ & 0.567 \\
\hline Septic prior to surgery, n (\%) & $39(78)$ & $11(22)$ & 0.047 \\
\hline Initial operative time ${ }^{\mathrm{e}}$, median (IQR) & $57(31-89)$ & $62(45-90)$ & 0.355 \\
\hline
\end{tabular}

$P$-values in bold denote significant values

APACHE Acute Physiologic Assessment and Chronic Health Evaluation, IQR Interquartile Range, LRINEC Laboratory Risk Indicator for Necrotizing fasciitis, qSOFA Quick Sequential Organ Failure Assessment, SD Standard Deviation, SOFA Sequential Organ Failure Assessment

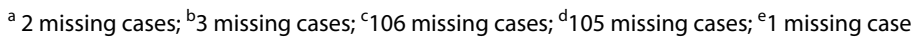

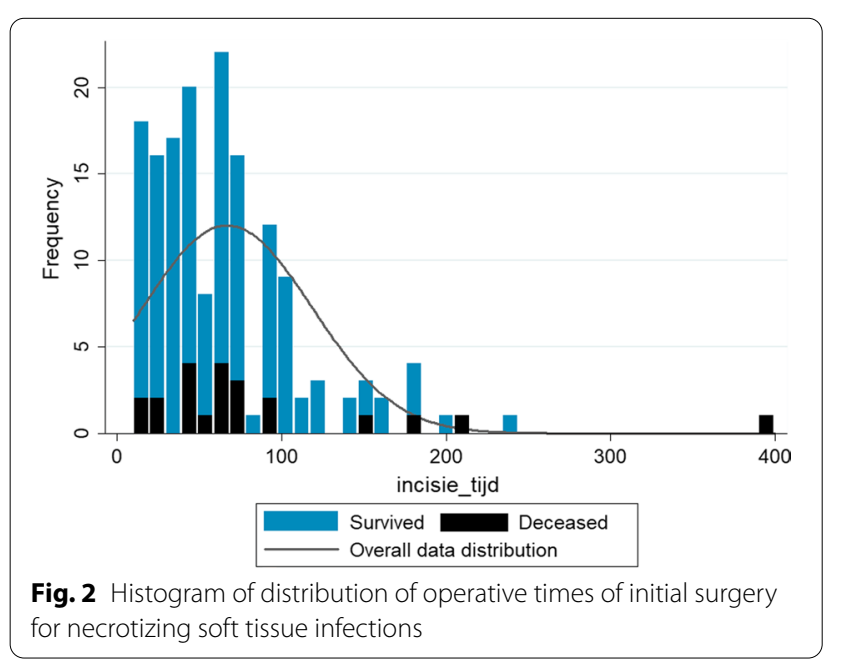

\section{Discussion}

This study found a median operative time of the initial debridement for NSTIs of 59 min, with most of the debridements (78\%) lasting no longer than $90 \mathrm{~min}$ and an overall 30 -day mortality rate of $14 \%$ in NSTI patients who underwent at least one debridement. Greater estimated TBSA affected and a higher ASA classification were independently associated with increased mortality, while the operative time did not demonstrate a direct relation with mortality, however the fifteen patients $(9 \%)$ who underwent surgery for $>140 \mathrm{~min}$ had a two-fold increase in mortality. Multivariate analysis showed that each $20 \mathrm{~min}$ of extra operative time during the initial debridement resulted in a 1.4-day increase in ICU stay and 3.3-days increase in hospital stay, even if corrected for the presence of sepsis prior to the surgery, estimated TBSA affected and ASA classification.

No other study has investigated the association between the operative time of the initial debridement for NSTIs and its outcomes. However, three prior studies have reported the mean operative time for their entire NSTI cohort. Hong et al. reported an mortality rate of $60 \%$ for fifteen septic Vibrio NSTI patient with all a NSTI affecting the extremities, which was associated with a mean duration of the initial debridement of $102 \mathrm{~min}$ [5]. Corman et al. found a mortality rate of $4 \%$ for Fournier gangrene with an associated mean duration of the initial surgery of $78 \mathrm{~min}$ and Elsaket et al. reported an mortality rate of $11.4 \%$ for Fournier gangrene associated with a mean duration of the initial debridement of $81 \mathrm{~min}$ $[4,6]$. Notable, all patients underwent a scrotectomy for source control in the study by Corman et al. and in the study by Elsaket et al. only $5 \%$ of the patients were septic upon presentation. As a result, and combined with the fact that those studies only investigated specific NSTI subtypes, these studies cannot directly be compared to our study which consisted of a heterogeneous population with mainly GAS infections in non-Fournier regions as we know that certain pathogens causing NSTIs tend 
Table 4 Treatment characteristics and outcomes of necrotizing soft tissue infection patients undergoing surgery

\begin{tabular}{|c|c|}
\hline & $\begin{array}{l}n=160 \\
(100 \%)\end{array}$ \\
\hline \multicolumn{2}{|l|}{ Surgical treatment } \\
\hline Time from surgical consult to surgery in hours ${ }^{\mathrm{a}}$, median (IQR) & $7(4-31)$ \\
\hline Operative time of initial surgery in minutes ${ }^{\mathrm{a}}$, median (IQR) & $59(35-90)$ \\
\hline Time in operating room for initial surgery in minutes ${ }^{\mathrm{b}}$, median (IQR) & $90(64-121)$ \\
\hline Amputation performed, $\mathrm{n}(\%)$ & $21(13)^{c}$ \\
\hline Amputation during initial surgery & $13(62)$ \\
\hline Skin sparing operating technique utilized, $n$ (\%) & $33(21)$ \\
\hline Intra-operative assessed frozen section and/or Gram stain, n (\%) & $36(23)$ \\
\hline Frozen section, $\mathrm{n}(\%)$ & $22(14)$ \\
\hline Gram stain, n (\%) & $24(15)$ \\
\hline Number of surgeries for NSTI within first 30 days ${ }^{d}$, median (IQR) & $3(2-5)$ \\
\hline Days from initial surgery to definitive wound closure in days ${ }^{d}$, median (IQR) & $25(10-56)$ \\
\hline \multicolumn{2}{|l|}{ Postoperative phase } \\
\hline Admitted to ICU, n (\%) & $110(67)$ \\
\hline Length of ICU stay in days ${ }^{\mathrm{e}}$, median (IQR) & $4(2-10)$ \\
\hline Length of hospital stay in days ${ }^{\mathrm{d}}$, median (IQR) & $24(15-42)$ \\
\hline \multicolumn{2}{|l|}{ Major infectious complication during hospital course, n (\%) } \\
\hline Sepsis & $88(55)$ \\
\hline Multiple organ dysfunction syndrome & $14(9)$ \\
\hline Deceased within 30 days after presentation, $\mathrm{n}(\%)$ & $22(14)$ \\
\hline Days from initial surgery to death in days, median (IQR) & $2(1-6)$ \\
\hline \multicolumn{2}{|l|}{ Cause of death, $n(\%)$} \\
\hline Sepsis & $11(50)$ \\
\hline Withdrawal of care & $10(45)$ \\
\hline Complication & $1(5)$ \\
\hline
\end{tabular}

ICUIntensive Care Unit, IQR Interquartile Range, NSTI Necrotizing Soft Tissue Infection

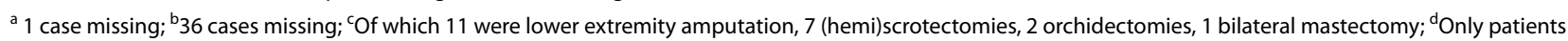
who survived hospital stay; ${ }^{\mathrm{e} O n l y}$ patients who survived ICU stay

to be associated with higher mortality rates, such as polymicrobial and Vibrio NSTIs [20]. Nonetheless, there is a shorter median operative time in this current cohort, with only $22 \%$ of the patients undergoing initial debridements for over $90 \mathrm{~min}$.

As seen in this study, NSTI patients often undergo surgery while they are physiologically compromised (e.g. metabolic acidosis, high sepsis scores), therefore it was postulated that these patients could also benefit from the damage control principles. The concept of damage control was first established to improve outcomes of severely injured trauma patients by obtaining rapid hemorrhage control and prevent contamination without definitive repairs during the first surgery, followed by resuscitation in attempt to prevent and/or reverse the pathophysiological triad of coagulopathy, metabolic acidosis and hypothermia ("lethal triad") [21]. Definitive surgical repair was reserved until after the goals of resuscitation were reached. In this study reduced operative times were not associated with a reduction in mortality, however, since this study is underpowered for this association, the hypothesis cannot yet be rejected nor confirmed. The lack of mortality reduction might be caused by the fact that the patients included in our study almost all had already a relatively short, and therefore already optimized, operating time. On the other hand, the reduced operative times were indeed associated with a significant shorter ICU and hospital stays, regardless of the presence of sepsis prior to surgery, the estimated TBSA affected and the ASA classification. The concept of reducing length of ICU and hospital stay by reducing operative times has not yet been described for NSTIs, but has been suggested for surgical procedures in trauma and general surgery [8, 22]. Procter et al. studied general surgical procedures and found that the odds ratio for ICU admission, adjusted for operative and patient risk variables, increased with 0.32 each half-hour of extra operative time and the hospital length of stay increased with $6 \%$ with each half hour extra operative time [8]. Harvin et al. studied emergency trauma laparotomies and found that 
Table 5 Factors associated with prolonged operative time for patients with necrotizing soft tissue infections

\begin{tabular}{|c|c|c|c|}
\hline & $\begin{array}{l}\text { Operative time in minutes, } \\
\text { if yes } \\
\text { median (IQR) }\end{array}$ & $\begin{array}{l}\text { Operative time in minutes, } \\
\text { if no } \\
\text { median (IQR) }\end{array}$ & $p$ value \\
\hline Location of NSTI & & & $0.158^{\mathrm{a}}$ \\
\hline Head/neck & $76(55-104)$ & $57(31-90)$ & 0.147 \\
\hline Trunk & $90(59-110)$ & $55(31-76)$ & 0.044 \\
\hline Perineum & $49(36-68)$ & $60(31-90)$ & 0.474 \\
\hline Upper extremity & $45(19-90)$ & $60(37-90)$ & 0.368 \\
\hline Lower extremity & $59(35-76)$ & $59(34-90)$ & 0.650 \\
\hline Estimated TBSA affected & & & $0.006^{b}$ \\
\hline$<2 \%$ & $38(26-65)$ & $60(37-90)$ & 0.089 \\
\hline $2-3 \%$ & $45(22-63)$ & $65(38-96)$ & 0.002 \\
\hline $4-5 \%$ & $72(38-100)$ & $56(30-76)$ & 0.134 \\
\hline$>6 \%$ & $71(43-100)$ & $47(29-75)$ & $<0.001$ \\
\hline Monomicrobial NSTI infection & $59(30-90)$ & $60(39-75)$ & 0.711 \\
\hline Amputation during initial surgery & $59(43-93)$ & $59(35-89)$ & 0.584 \\
\hline Skin sparing operating technique utilized & $46(30-90)$ & $60(36-89)$ & 0.715 \\
\hline Intra-operative assessed frozen section and/or Gram stain & $87(63-106)$ & $46(29-73)$ & $<0.001$ \\
\hline
\end{tabular}

$P$-values in bold denote significant values

IQR Interquartile range, NSTI Necrotizing Soft Tissue Infection, TBSA Total Body Surface Area

${ }^{a}$ Kruskal Wallis test; ${ }^{b}$ Chi-squared for trend

damage control principles when applied correctly significantly increased the probability of a shorter ICU and hospital stay compared to when a definitive laparotomies was performed [22]. Furthermore, this study showed that besides operative time, sepsis prior to surgery is also independently associated with prolonged ICU and hospital stay, however this variable is often non-modifiable.

The principle of damage control is based on the philosophy of doing only what is necessary in order not to exhaust the physiological reserves of the patient. Therefore, it can be questioned if performing debridement utilizing the skin sparing technique for NSTIs is doing something more than necessary [23]. In the current study, the skin sparing technique did not result in median prolonged operative times, which might indicate that the technique was used in the proper cases. Nevertheless, a case of 400 min was documented with fatal outcome.

The use of intra-operative diagnostics such as frozen section or Gram stain have also been argued to cause treatment delay, since the time waiting on the results could also be used for debridement, however this statement was not yet investigated in a clinical study [24, 25]. This study found indeed a prolonged operative time with a difference in medians of $41 \mathrm{~min}$, which is to be expected since it can take up to $30 \mathrm{~min}$ to process and assess a frozen section [12, 13]. However, the time to diagnosis was significantly shorter in cases that used intra-operative diagnostics (difference in medians of $3 \mathrm{~h}$ ), which enables timely debridement. However, these intra-operative diagnostic modalities should only be used if indicated: in ambivalent cases to prevent unnecessary debridements in non-NSTI cases or prevent delay and/or refrainment of debridement due to less evident macroscopic findings in NSTI cases [26].

The findings of this study need to be interpreted in context of its limitations. First, the retrospective nature of this study resulted in a substantial amount of missing dating for certain variables, especially limiting our ability to use blood gasses results to calculate SOFA and APACHE II scores and to determine the degree of sepsis/septic shock. Especially for these variables, selection bias is likely present, because patient presenting without systemic toxicity will not always have a comprehensive laboratory work-up. Second, the TBSA was estimated based on operative notes and might be overor underestimated in certain patients. Third, other factors associated with mortality (such as pathogen or time to surgery) could not reliably be investigated in this study, since only patients undergoing surgery were included and it is known that is common that some patients with NSTIs are already deceased before they can undergo surgery. Furthermore, this study is underpowered regarding the main objective, this warrants further research in bigger cohorts. However, the strengths of this study are the fairly large sample size 
Table 6 Association of operative time per 20 min on various outcomes of necrotizing soft tissue infections

\begin{tabular}{|c|c|c|c|}
\hline & $\begin{array}{l}\beta \text { coefficient } \\
(95 \% \mathrm{Cl})\end{array}$ & Standard error & $p$ value* \\
\hline \multicolumn{4}{|l|}{ Mortality $(n=150)$} \\
\hline Operative time (per $20 \mathrm{~min}$ ) & $0.14(-0.06$ to 0.33$)$ & 0.10 & 0.170 \\
\hline Estimated total body surface area affected (in \%) & $0.16(0.04$ to 0.27$)$ & 0.06 & 0.007 \\
\hline Septic prior to surgery & $0.49(-0.06$ to 1.59$)$ & 0.56 & 0.391 \\
\hline ASA classification & 1.01 (0.31 to 1.72$)$ & 0.36 & 0.005 \\
\hline \multicolumn{4}{|l|}{ Amputation required after initial surgery $(n=150)$} \\
\hline Operative time (per $20 \mathrm{~min}$ ) & $0.11(-0.012$ to 0.35$)$ & 0.12 & 0.356 \\
\hline Estimated total body surface area affected (in \%) & $0.03(-0.13$ to 0.20$)$ & 0.09 & 0.696 \\
\hline Septic prior to surgery & $0.49(-1.04$ to 2.02$)$ & 0.78 & 0.528 \\
\hline ASA classification & $0.26(-0.62$ to 1.14$)$ & 0.45 & 0.568 \\
\hline \multicolumn{4}{|l|}{ Length of ICU stay $(n=104)$} \\
\hline Operative time (per 20 min) & 1.43 (0.46 to 2.40$)$ & 0.49 & 0.004 \\
\hline Estimated total body surface area affected (in \%) & $0.29(-0.33$ to 0.91$)$ & 0.31 & 0.352 \\
\hline Septic prior to surgery & $9.19(4.91$ to 13.47$)$ & 2.16 & $<0.001$ \\
\hline ASA classification & $-1.31(-3.67$ to 1.06$)$ & 1.19 & 0.275 \\
\hline \multicolumn{4}{|l|}{ Length of hospital stay $(n=129)$} \\
\hline Operative time (per 20 min) & 3.25 (0.23 to 6.27$)$ & 1.53 & 0.035 \\
\hline Estimated total body surface area affected (in \%) & $6.37(4.19$ to 8.55$)$ & 1.10 & $<0.001$ \\
\hline Septic prior to surgery & 17.17 (3.41 to 30.94) & 6.96 & 0.015 \\
\hline ASA classification & $6.84(-0.69$ to 14.37$)$ & 3.80 & 0.074 \\
\hline \multicolumn{4}{|l|}{ Number of surgeries within first 30 days $(n=145)$} \\
\hline Operative time (per 20 min) & $0.01(-0.14$ to 0.16$)$ & 0.08 & 0.873 \\
\hline Estimated total body surface area affected (in \%) & $0.25(0.13$ to 0.37$)$ & 0.06 & $<0.001$ \\
\hline Septic prior to surgery & $-0.24(-1.05$ to 0.58$)$ & 0.41 & 0.565 \\
\hline ASA classification & $-0.16(-0.58$ to 0.25$)$ & 0.21 & 0.438 \\
\hline \multicolumn{4}{|l|}{ Days until definitive wound closure $(n=120)$} \\
\hline Operative time (per $20 \mathrm{~min}$ ) & $-2.77(-7.64$ to 2.09$)$ & 2.46 & 0.262 \\
\hline Estimated total body surface area affected (in \%) & $-2.52(-6.01$ to 0.96$)$ & 1.76 & 0.154 \\
\hline Septic prior to surgery & $8.32(-14.40$ to 31.05$)$ & 11.47 & 0.470 \\
\hline ASA classification & $11.41(-1.27$ to 24.09$)$ & 6.40 & 0.077 \\
\hline
\end{tabular}

Bold values denote significant values

$\mathrm{ASA}=$ American Society of Anesthesiologists; ICU = Intensive Care Unit

compared to other NSTI cohorts and that it is the first study assessing the consequences of prolonged operative times of the initial debridement for NSTIs.

\section{Conclusions}

Prolonged initial surgery did not result in a higher mortality rate, possible because of a short duration of surgery in most studied patients. However, a prolonged operative time was associated with a prolonged ICU and hospital stay. The goal remains to prevent treatment delay and to perform an efficient and adequate debridement to obtain source control followed by adequate resuscitation in the ICU. Treating physicians should aim to optimize prompt surgical debridement and start of adequate intravenous antibiotics upon presentation and minimize operative times, since reduced hospital stays will reduce health care costs and has a positive impact on the patient outcomes.

\section{Abbreviations}

APACHE: Acute Physiologic Assessment and Chronic Health Evaluation; ASA: American Society for Anesthesiologists; Cl: Confidence Interval; CK: Creatine Kinase; CRP: C-Reactive Protein; ICD: International Classification of Disease; ICU: Intensive Care Unit; IQR: Interquartile Range; LD: Lactate Dehydrogenase; LRINEC: Laboratory Risk Indicator for Necrotizing fasciitis; MODS: Multiple Organ Disfunction Syndrome; NSTI: Necrotizing Soft Tissue Infection; qSOFA: Quick Sequential Organ Failure Assessment; SD: Standard Deviation; SOFA: 
Sequential Organ Failure Assessment; STROBE: Strengthening the Reporting of Observational Studies in Epidemiology; TBSA: Total Body Surface Area; WBC: White Blood Cell.

\section{Supplementary Information}

The online version contains supplementary material available at https://doi. org/10.1186/s12893-021-01456-0.

Additional file 1. Methods of identifying patients with necrotizing soft tissue infections.

\section{Acknowledgements}

Not applicable.

\section{Authors' contributions}

$\mathrm{FH}$ and FN conceived the study. FN collected and analyzed the data. FH and $\mathrm{MvH}$ critically evaluated the data analysis for methodological and statistical accuracy. FN wrote the first draft of the manuscript, which was critically revised by FH, MvH, JK and PvK. All authors read and approved the final manuscript.

\section{Funding}

Not applicable.

\section{Availability of data and materials}

The dataset used and analysed during the current study are available from the corresponding author on reasonable request.

\section{Declarations}

\section{Ethics approval and consent to participate}

The institutional review board (Medisch Ethische Toetsingscommissie (METC) Utrecht) of the initiating hospital (University Medical Hospital Utrecht) provided a waiver (WAG/mb/20/012110) for retrospective data collection.

\section{Consent for publication}

Not applicable.

\section{Competing interests}

The authors declare that they have no competing interests.

\section{Author details}

'Department of Surgery, University Medical Center Utrecht, Utrecht, The Netherlands. ${ }^{2}$ Department of Surgery, Diakonessenhuis, The Netherlands. ${ }^{3}$ Department of Surgery, St. Antonius Hospital, Nieuwegein, The Netherlands.

${ }^{4}$ Department of Surgery, Meander Medical Center, Hoogland, The Netherlands.

\section{Received: 11 August 2021 Accepted: 24 December 2021}

Published online: 08 January 2022

\section{References}

1. Wong $\mathrm{CH}$, Chang HC, Pasupathy S, Khin LW, Tan JL, Low CO. Necrotizing fasciitis: clinical presentation, microbiology, and determinants of mortality. J Bone Jt Surg. 2003;85(8):1454-60.

2. Sarani B, Strong M, Pascual J, Schwab CW. Necrotizing fasciitis: current concepts and review of the literature. J Am Coll Surg. 2009;208(2):279-88

3. Nawijn F, Smeeing D, Houwert R, Leenen L, Hietbrink F. Time is of the essence when treating necrotizing soft tissue infections: a systematic review and meta-analysis. World J Emerg Surg. 2020;15:4
4. Corman JM, Moody JA, Aronson WJ. Fournier's gangrene in a modern surgical setting: improved survival with aggressive management. BJU Int. 1999:84(1):85-8.

5. Hong G-L, Dai X-Q, Lu C-J, Liu J-M, Zhao G-J, Wu B, et al. Temporizing surgical management improves outcome in patients with Vibrio necrotizing fasciitis complicated with septic shock on admission. Burns. 2014;40(3):446-54

6. Elsaket AE, Maharajh S, Urry RJ. The presentation, management and outcomes of Fournier's gangrene at a tertiary urology referral centre in South Africa. S Afr Med J. 2018;108(8):671-6.

7. Matsuyama T, Iranami H, Fujii K, Inoue M, Nakagawa R, Kawashima K. Risk factors for postoperative mortality and morbidities in emergency surgeries. J Anesth. 2013:27(6):838-43.

8. Procter LD, Davenport DL, Bernard AC, Zwischenberger JB. General surgical operative duration is associated with increased risk-adjusted infectious complication rates and length of hospital stay. J Am Coll Surg. 2010;210:1

9. Cheng H, Clymer JW, Po-Han Chen B, Sadeghirad PhDB, Ferko NC, Cameron CG, et al. Prolonged operative duration is associated with complications: a systematic review and meta-analysis. J Surg Res. 2018:229:134-44

10. Lamb CM, Macgoey P, Navarro AP, Brooks AJ. Damage control surgery in the era of damage control resuscitation. Br J Anaesth. 2014:113(2):242-9.

11. Benz D, Balogh ZJ. Damage control surgery: Current state and future directions. Curr Opin Crit Care. 2017;23(6):491-7.

12. Nawijn F, Hietbrink F, van Dijk MR. Getting it right the first time: frozen sections for diagnosing necrotizing soft tissue infections. World J Surg. 2021:45(1):148-59.

13. Hietbrink F, Bode LG, Riddez L, Leenen LPH, van Dijk MR. Triple diagnostics for early detection of ambivalent necrotizing fasciitis. World J Emerg Surg. 2016;11:51

14. Livingston $\mathrm{EH}$, Lee $\mathrm{S}$. Percentage of burned body surface area determination in obese and nonobese patients. J Surg Res. 2000;91(2):106-10.

15. Singer M, Deutschman CS, Seymour C, Shankar-Hari M, Annane D, Bauer $M$, et al. The third international consensus definitions for sepsis and septic shock (sepsis-3). JAMA - J Am Med Assoc. 2016;315(8):801-10.

16. Suzuki H, Muramatsu K, Kubo T, Kawasaki M, Fujitani T, Tsukamoto M, et al Factors associated with mortality among patients with necrotizing softtissue infections: an analysis of 4597 cases using the Diagnosis Procedure Combination Database. Int J Infect Dis. 2021;102:73-8.

17. Tantirat $P$, Rattanathumsakul T, Praekunatham H, Pachanee K, Suphanchaimat R. Epidemiological situation of necrotizing fasciitis and factors in Thailand and factors associated with its morbidity and mortality, 2014-2018. Risk Manag Healthc Policy. 2020;13:1613-24.

18. Al-Qurayshi Z, Nichols RL, Killackey MT, Kandil E. Mortality Risk in Necrotizing Fasciitis: National Prevalence, Trend, and Burden. Surg Infect (Larchmt). 2020.

19. Khamnuan P, Chongruksut W, Jearwattanakanok K, Patumanond J, Yodluangfun S, Tantraworasin A. Necrotizing fasciitis: risk factors of mortality. Risk Manag Healthc Policy. 2015:8:1-7.

20. Nawijn F, Wassenaar ECE, Smeeing DPJ, Vlaminckx BJM, Reinders JSK, Wille J, et al. Exhaustion of the immune system by Group A Streptococcus necrotizing fasciitis : the occurrence of late secondary infections in a retrospective study. Trauma Surg Acute Care Open 2019·4(1):e000272.

21. Hecker A, Reichert M, Reuß CJ, Schmoch T, Riedel JG, Schneck E, et al. Intra-abdominal sepsis: new definitions and current clinical standards. Langenbeck's Arch Surg. 2019;404(3):257-71.

22. Harvin JA, Sharpe JP, Croce MA, Goodman MD, Pritts TA, Dauer ED, et al. Effect of damage control laparotomy on major abdominal complications and lengths of stay: a propensity score matching and bayesian analysis. J Trauma Acute Care Surg. 2019:87(2):282-8.

23. Tom LK, Wright TJ, Horn DL, Bulger EM, Pham TN, Keys KA. A skin-sparing approach to the treatment of necrotizing soft-tissue infections: thinking reconstruction at initial debridement. J Am Coll Surg. 2016;222(5):e47-60.

24. Sartelli M, Guirao X, Hardcastle TC, Kluger Y, Boermeester MA, Raşa K, et al. 2018 WSES/SIS-E consensus conference: recommendations for 
the management of skin and soft-tissue infections. World J Emerg Surg. 2018;13:58.

25. Anaya D, Dellinger E. Necrotizing soft-tissue infection: diagnosis and management. Clin Infect Dis. 2007;44(5):705-10,

26. Nawijn F, Houwert RM, van Wessem KPJ, Simmermacher RKJ, Govaert GAM, van Dijk MR, et al. A 5-year evaluation of the implementation of triple diagnostics for early detection of severe necrotizing soft tissue disease: a single-center cohort study. World J Surg. 2019;43(8):1898-905.

\section{Publisher's Note}

Springer Nature remains neutral with regard to jurisdictional claims in published maps and institutional affiliations.

Ready to submit your research? Choose BMC and benefit from:

- fast, convenient online submission

- thorough peer review by experienced researchers in your field

- rapid publication on acceptance

- support for research data, including large and complex data types

- gold Open Access which fosters wider collaboration and increased citations

- maximum visibility for your research: over $100 \mathrm{M}$ website views per year

At $\mathrm{BMC}$, research is always in progress.

Learn more biomedcentral.com/submissions 